\title{
Learning to Think and Create \\ Outside the Box: Using Digital Media in a Blended Theatre Course
}

\author{
Rebecca Holderness and Matthew Russell \\ University of Wisconsin-Milwaukee \\ 2400 East Kenwood Blvd. \\ Milwaukee, WI, 53201, USA \\ rph2@uwm.edu, russelmr@uwm.edu
}

\section{INTRODUCTION}

This interactive course demonstration considers the innovative use of easily available digital media technologies to illuminate complex connections between community, history, design and performance in the performing arts.

In essence, the demonstration will reference and consider the theory and practice of teaching online with these media, and discuss the innovative project ideas that use digital media to inspire and model inductive and deductive reasoning within a theatre arts course.

\section{DESCRIPTION OF PROJECT}

The course rational supports visual, malleable, and digitally performative methods to teach reasoning and increase creative output in theatre study. Course content demonstrates methods based in learning theory and including use of haptic visual collaborative media to clarify ideas and support innovative thinking.

The rationale for the creation of such a course is that a "Great Ideas" oriented and blended introductory course will better support both theatre and general student development by not focusing simply on data but on the methods of inquiry, synthesis of ideas and awareness of individual point of view. In seeking to develop a more participatory culture of learning through the use of digital technologies, we anticipate that this approach will deepen inquiry at more advanced levels and inspire a growing population of theatremakers to consider methods for conceptualizing emergent theatre practice.

\section{DEMONTRATION OUTLINE}

In order to offer an insight into the experience of the course for students, a set of visualization tools will be used to create examples of theatrical text and the ways in which students will be encouraged to produce digital interpretations and reimaginings of existing theatrical genres and structures.

During the demonstration, examples of different digital representations of theatrical terminology and visualizations of theatrical text will be displayed and discussed within a framework of talking about the theatre otherwise with students and in an effort to elicit different, more creative responses from students. Following the lead of groups such as the $<<$ Simulated Environment For The Theatre>> collaborative of Canadian university theatre researchers and the tools they have devised (e.g., Voyant Tools, the Mandala browser), this demonstration will discuss and display alternate ways of representing and visualizing theatrical text and space.

Replacing the traditional lecture and textbook format nominally associated with introductory theatre courses, these tools will be used in order to encourage students to read differently and see the revolutionary characteristics of theatrical text. Reading differently will encourage students to enter into dialogic exchanges with the texts and thus into imagining alternate spatial representations of these texts. This demonstration will conclude with a discussion of the final projects that students will be encourage to create in a variety of group settings, including a survey of tools and examples that will be offered to students in their efforts to recreate or remix the elements of the texts, genres and traditions with which they have engaged in the first portion of the course. 